\title{
Genetics of Prostate Cancer
}

Kai Qi Zhang, Personalized Medicine Research Center, Marshfield Medical Research Foundation, Marshfield, Wisconsin Sherry A. Salzman, Personalized Medicine Research Center, Marshfield Medical Research Foundation, Marshfield, Wisconsin D. J. Reding, MD, Departments of Hematology and Oncology, Marshfield Clinic, Marshfield, Wisconsin

Brian K. Suarez, PhD, Departments of Psychiatry and Genetics, Washington University School of Medicine, St. Louis, Missouri William J. Catalona, MD, Division of Urologic Surgery, Washington University School of Medicine, St. Louis, Missouri James K. Burmester, PhD, Personalized Medicine Research Center, Marshfield Medical Research Foundation, Marshfield, Wisconsin

\section{ABSTRACT}

Prostate cancer is the most frequently diagnosed visceral cancer of men, responsible for approximately 40,000 deaths in adult males per year. To identify the genetic causes of prostate cancer, we performed a whole genome scan of affected sib pairs, using DNA markers spaced evenly across the human genome. We demonstrated that regions on chromosomes 1, 4, 5, 7, 8, 11, 16 and 19 might harbor genes that predispose individuals to prostate cancer and may affect tumor growth rate and tumor aggressiveness. Here we present DNA sequence analysis of KIAA 0872 and 17- $\beta$ hydroxysteroid dehydrogenase that are located on chromosome 16 within the mapped region, and we demonstrate that neither of these genes carries mutations in the protein coding region or their splice junction sites. These results suggest that these genes are less likely to be associated with the cause of familial prostate cancer.

\section{INTRODUCTION}

Prostate cancer is the second leading cause of cancer mortality for men in the U.S. with a rate of 26 deaths per $100,000 .{ }^{1}$ Although prostate cancer is potentially curable in its early stages, treatment of advanced hormone-refractory prostate cancer is ineffective, making early detection and treatment of disease a necessity. ${ }^{2}$ Unfortunately, approximately $30 \%$ of men with prostate cancer have tumor that has spread beyond the prostate gland at the time of diagnosis. Despite the impressive response of metastases to androgen hormone deprivation, the survival rate is dismal, with greater than $90 \%$ of these patients dying from their cancer. ${ }^{3}$ Screening tests for prostate cancer include digital rectal examination, transrectal ultrasonography, and measurement of prostate-specific antigen. However, these tests often do not detect the tumors before they have spread. The development of additional tests for earlier identification of prostate tumors will be extremely important. 4,5

RECEIVED: December 20, 2001

REPRINT REQUESTS:

James K. Burmester, PhD

Personalized Medicine Research Center

Marshfield Medical Research Foundation

1000 North Oak Avenue

Marshfield, WI 54449

Telephone: 715-389-4368

Fax: $715-389-3808$

Email: burmester.james@marshfieldclinic.org
REVISED AND ACCEPTED: February 15, 2002

\section{KEYWORDS:}

17 $\beta$-hydroxysteroid dehydrogenase; Chromosome 16;

Whole genome scan; Mutation analysis

GRANT SUPPORT:

Funded by a grant from the Urological Research Foundation and USPH grant MH31302 and DAMD 17-00-1-0108 from the United States Army. 
One of every six men will be diagnosed with prostate cancer in his lifetime. Factors that increase a man's risk for prostate cancer include increasing age, race, family history and lifestyle. Men over the age of 65 are at highest risk, yet $25 \%$ of cases are diagnosed under the age of 65 . AfricanAmericans have the highest rate and are 50\% more likely than white males to be diagnosed with prostate cancer and twice as likely to die from this disease. ${ }^{6}$

Continuous androgen stimulation is necessary for development and maintenance of the prostate gland. Thus, genes that affect the synthesis and metabolism of androgens may modulate risk for prostate cancer or the tendency of a tumor to progress to the more aggressive forms of this disease. ${ }^{7}$ Similarly, genes regulated by androgens are also likely to be important in prostate cancer development.

$17 \beta$-hydroxysteroid dehydrogenase (17 $\beta$-HSD) is expressed in prostate and also extragonadal tissues, including liver and kidney, and catalyzes the conversion between the low-activity sex steroids, androstenedione and $5 \alpha$-androstanedione, and the more potent forms, testosterone and $5 \alpha$-dihydrotestosterone. ${ }^{8} 17 \beta$-HSD activity is essential for testosterone synthesis in the gonads and may also regulate the concentration of active sex steroids locally in target cells such as prostate. $17 \beta$-HSD is most efficient in the oxidative inactivation of testosterone and $5 \alpha$-androstanedione to their less active 17keto metabolites. Our hypothesis is that mutations or polymorphisms that inactivate or significantly reduce the activity of $17 \beta$-HSD would increase androgen levels leading to increased hyperplasia within the prostate and ultimately more cancer due to the increased proliferation of cells.

A model of the known somatic mutations occurring during prostate cancer progression was proposed by Pienta and colleagues. ${ }^{9}$ In this model, normal prostate epithelium progresses to localized prostate cancer, then to metastatic prostate cancer, and finally to androgen-independent cancer. Proposed early genetic events leading to localized prostate cancer are germline changes, methylation changes, loss of glutathione-stransferase pi gene, loss of heterozygosity (LOH) of chromosome $8 \mathrm{p}$ and changes in the number of androgen receptor $\mathrm{CAG}$ repeats. Proposed changes leading to metastatic disease are loss of chromosome 16q, loss of Rb, loss of KAI, p53 inactivation and altered E-cadherin expression. Androgen receptor mutations are associated with the progression to androgen independent cancer. Mutations of PTEN, a protein tyrosine phosphatase, ${ }^{10}$ and of TSG101, a putative transcription factor, ${ }^{11}$ are frequent in prostate tumors. LOH studies of primary tissue have identified putative tumor suppressor genes at chromosomes $4,7,8,10,11,13 \mathrm{q}, 16 \mathrm{q}$, and $17 .{ }^{12-22}$

The genetics of inherited prostate cancer are poorly understood. Family history of prostate cancer is a strong predictor of disease with inherited germline mutations being estimated to account for approximately $9 \%$ of all cancers and $45 \%$ of cases in men younger than 55.23,24 Linkage mapping studies have identified chromosomal regions 1q24-25, 1q42.2-43, 1p36, Xq11, Xq27-28, 20q13 and 11p that correlate with inherited disease. ${ }^{25-31}$ The specific genes involved in prostate cancer development within these regions are largely unknown. Mutation of RNASEL at 1q24-25 segregates with two HPC-1 linked families. ${ }^{32}$ However, mutations were not identified in other families linked to HPC1 and inactive RNASEL alleles are present at low frequency in the general population. The gene HPC2/ELAC2 on chromosome 17p was found to be associated with increased risk for prostate cancer. ${ }^{33,34}$ However, analysis of this gene in families with prostate cancer failed to show excess clustering of the abnormal allele, suggesting that the amino acid change does not cause prostate cancer. ${ }^{35}$

To identify genes that predispose families to prostate cancer, we have performed a linkage mapping study of affected sib pairs. ${ }^{36}$ In this study, we collected blood-derived DNA from approximately 600 affected sib pairs identified at Washington University in St. Louis. For each patient, we recorded the vital statistics such as age, family history of prostate cancer and breast cancer, and tumor stage and grade at diagnosis. DNA samples were tested at the Marshfield Medical Research Foundation using DNA markers spaced evenly across the human genome. Analysis identified the highest probability score on the long arm of chromosome 16 when the data were analyzed without stratification. Regions identified following stratification of the patient population according to various clinical parameters include $1 \mathrm{p} 35.1$ for families with breast cancer, $4 \mathrm{q}$ in late-age-at-onset patients, and $5 \mathrm{q}, 7 \mathrm{q}$ and $19 q$ in patients with aggressive disease. ${ }^{37}$

Here we report sequence analysis data regarding two genes within the region of interest on chromosome 16. For these studies, DNA samples were sequenced from patients likely to carry a mutated gene in this region, and from control patients who did not show significant association with this chromosomal region. Our results do not find a causative mutation in either of the candidate genes, 17 $\beta$-HSD or KIAA 0872, a cDNA clone of unknown function. They demonstrate that additional DNA sequencing within the mapped region on chromosome 16 is necessary to find the DNA sequence that predisposes men to prostate cancer.

\section{METHODS}

Families were ascertained from Washington University Medical School when two or more documented cases of prostate cancer were present in the family. The Institutional Review Boards at both Washington University Medical School and Marshfield Medical Research Foundation approved the research protocols and all patients provided informed consent. The diagnosis of prostate cancer was confirmed directly by a pathologist or through examination of medical records. Determination of age-at-diagnosis and health status of other 
family members was made from examination of medical records. Tumors were graded using the Gleason System. All patients were Caucasian.

The coding region of KIAA 0872 was sequenced to determine if mutations were present that might contribute to the development of prostate cancer. Genomic DNA extracted from blood samples of 18 with prostate cancer patients with high-frequency of allele sharing on 16q, and blood samples from 18 prostate cancer patients with a low-frequency of allele sharing on 16q, were sequenced along with 3 prostate cancer cell lines (DU145, LNCaP, PC-3) and 9 genomic DNAs from donors without prostate cancer. Patients with a high-frequency of allele sharing are those in which a sib pair is likely to share both of their extended haplotypes identicalby-descent, whereas low-frequency means that a sib pair is inferred to share neither haplotypes identical-by-descent. Five exons of KIAA 0872 were determined by aligning the cDNA sequence (GenBank accession \# AB020679) with the chromosome 16 genomic sequence (GenBank accession \# AC009139) using the BLAST 2 Sequences program from National Center for Biotechnology Information (http://www.ncbi.nlm.nih.gov/blast/bl2seq/bl2.html). The exons were amplified by polymerase chain reaction using the oligo primers shown in table 1. Exons 1, 2, 4 and 5 were amplified entirely in one reaction with one primer set. Exon 3 was amplified in segments with multiple primer sets (table 1). Amplification products of the expected size were excised and purified from a $1 \%$ agarose gel. The purified amplification products were sequenced using the Thermo Sequenase Radiolabeled Terminator Cycle Sequencing Kit (USB,

Table 1. PCR and sequencing oligo primers for mutation analysis of KIAA 0872.

\begin{tabular}{|c|c|c|c|}
\hline Exon & $\begin{array}{c}\text { Primer } \\
\text { set }\end{array}$ & $\begin{array}{l}\text { Forward } \\
\text { primer }\end{array}$ & $\begin{array}{c}\text { Reverse } \\
\text { primer }\end{array}$ \\
\hline
\end{tabular}

\begin{tabular}{|c|c|c|c|}
\hline 1 & & 5 '-ctc gat tccg cct ccc act & $5^{\prime}$-gga ttc ctt tta aga ccc cac $t$ \\
\hline 2 & & 5'-aca tgc agt gac cca cca g & 5 '-cag tca tgt ccc cca ttc $t$ \\
\hline \multirow[t]{5}{*}{3} & A & $5^{\prime}-\operatorname{ccc} \operatorname{cct}$ tct tac ccc ttc tt & 5'-gtc cag aag tcg gtc cag \\
\hline & B & 5'-act atg acc tcc gcc gcc & 5'-ccg cct act gcc agc act \\
\hline & C & 5'-gcg ctc ctc cga cgt tg & 5'-agg cag aca ttc ata gca \\
\hline & $\mathrm{D}$ & 5'-aac cct gat ggt ttt ttc $t$ & $5^{\prime}$-ggc gcc cga cag cct gca \\
\hline & $E$ & $5^{\prime}$-cct cat cag cca gtg ctc & 5'-acc cag cca gtg cct tag gg \\
\hline 4 & & $5^{\prime}$-cct gga cta acc ttg tcc & $5^{\prime}$-tca ctc aga gcc ctg ccc \\
\hline 5 & & 5'-cca gct ctg gcc atc tga & 5'-ccc aca cac att tcc ggg \\
\hline
\end{tabular}

Cleveland, $\mathrm{OH}$ ) with the primers shown below. Sequences were analyzed for mutations by electrophoresis through a $6.5 \%$ polyacrylamide sequencing gel.

The exons, as described by Labrie and colleagues, ${ }^{38}$ of the human type II $17 \beta$-HSD were analyzed for mutations potentially contributing to prostate cancer. Exons from the genomic DNA of one normal donor, 3 prostate cancer cell lines (DU145, LNCaP, PC-3) and 22 prostate cancer patients with low-frequency of allele sharing on 16q and 22 prostate cancer patients with high-frequency of allele sharing on 16q were amplified and sequenced (as described previously) with the primer sets shown in table 2 .

Additionally, the 5' untranslated region presumably containing the $17 \beta$-HSD promoter was screened for mutations predisposing to prostate cancer. Segments of the promoter region were amplified and sequenced as described previously with primer sets listed in table 3 .

Differences in the expression levels of both the KIAA 0872 gene and $17 \beta-H S D$ gene between normal and cancerous prostate cells were examined by Northern hybridization of total RNA from normal prostate cells, 3 normal prostate cell lines and 4 cancerous prostate cell lines. Total RNA from normal prostate was purchased from Clontech (Palo Alto, CA). Normal prostate cell lines (PZ-HPV7 and PNT2) and cancerous prostate cell lines (DU145, LNCaP, PC-3 and Ca-HPV10) were purchased from the American Type Culture Collection (ATCC, Manassas, VA). Total RNA was extracted from cells using Trizol reagent as described by the manufacturer (Life Technologies, Inc., Rockville, MD). Four micrograms of total

Table 2. PCR and sequencing oligo primers for mutation analysis of $17 \beta-H S D$.

\begin{tabular}{ccc}
\hline Exon & $\begin{array}{c}\text { Forward } \\
\text { primer }\end{array}$ & $\begin{array}{c}\text { Reverse } \\
\text { primer }\end{array}$ \\
\hline 1 & 5'-cct tgg tat tta tgt tga a & 5'-tca gtg aaa att gta gca \\
2 & 5'-cct gtc act ctg gtt tga & 5'-gag tgg ggg ggc atg ttc \\
3 & 5'-att cac ttc ctc ttc ca & 5'-atg cca tga gcc atg tct t \\
4 & 5'-ttc ctc tct tat aag aat g & 5'-gtt gag tga att gct ccc \\
5 & 5'-aat aag tcc ttt ctc aca & 5'-cag gcc ctg atc ttc tag \\
6 & 5'-ttt att gga tga aca aat & 5'-cag acc aag agg acc ttc \\
7 & 5'-ctt ccc aac aga gac aag & 5'-aaa gta cta aat caa \\
\hline
\end{tabular}


Table 3. Amplification and sequencing oligo primers for mutation analysis of putative promoter region of 17ß-HSD.

\begin{tabular}{ccc}
$\begin{array}{c}\text { Prime } \\
\text { Set }\end{array}$ & $\begin{array}{c}\text { Forward } \\
\text { Primer }\end{array}$ & $\begin{array}{c}\text { Reverse } \\
\text { Primer }\end{array}$ \\
\hline 1 & 5'-gat tag att tga ata gag gg & 5'-agt ctt gca gcc tga tct ca \\
2 & 5'-gaa tag aat gct tag ggg ca & 5'-agg gat atg aaa gta gag ga \\
3 & 5'-gac caa agc act ttc ctc ta & 5'-atg aca gtc cac ctc tgg ag \\
4 & 5'-ccc tgg cat gtt tcc act cag gc & 5'-gcc tga gtg gaa cat gcc a \\
\hline
\end{tabular}

RNA for each sample mentioned above were equalized for $\beta$ actin signals prior to loading on formaldehyde electrophoresis gels. ${ }^{39}$ Total RNA, after electrophoretic separation, was transferred and UV-crosslinked to a nylon membrane.

Hybridization probes were produced by amplifying Exon 5 of KIAA 0872 and by excising the insert from IMAGE (available from Research Genetics, Huntsville, AL) clone for 17 $\beta$ HSD. Probes were labeled with $\alpha-32$ P-dCTP (NEN, Boston, MA) using the Random Prime Labeling Kit (Life Technologies, Inc., Rockville, MD). Nylon membrane carrying total RNA was prehybridized in ExpressHyb hybridization buffer (Clontech) for 30 minutes at $65^{\circ} \mathrm{C}$. Buffer was replaced with fresh ExpressHyb buffer containing $1 \times 10^{6}$ $\mathrm{cpm}$ of heat denatured $\alpha-32 \mathrm{P}$ labeled probe and hybridization carried out for 60 minutes at $65^{\circ} \mathrm{C}$. The membrane was rinsed with wash buffer containing $2 \mathrm{X}$ sodium chloride, sodium citrate buffer (SSC) and $0.05 \%$ sodium dodecyl sulfate (SDS) and then washed $2 \times 15$ minutes at room temperature with continuous shaking. Two additional washes at $56^{\circ} \mathrm{C}$ were performed in wash buffer containing $0.1 \mathrm{X} \mathrm{SSC}, 0.1 \%$ SDS. The membrane was rinsed briefly with $2 \mathrm{X}$ SSC and exposed to phosphorimaging screen (Molecular Dynamics, Sunnyvale, CA).

\section{RESULTS}

Northern hybridization with a human type II $17 \beta-H S D$ probe showed significant decreases in the amount of $17 \beta$-HSD message in the cancer cell lines LNCaP, DU145, PC-3 as compared to the normal prostate message (figure 1). The cancer cell line Ca-HPV10 showed a slightly increased level of expression versus the normal prostate. One of the two normal prostate cell lines, PNT2, showed expression levels similar to the normal human prostate message, but the message from the normal human prostate epithelial cell RNA (Clonetics) was significantly decreased. Based on these results, we sequenced genomic DNA from prostate cancer patients showing genetic linkage to chromosome 16q to identify inherited mutations or polymorphisms that may cause reduced $17 \beta$ HSD expression.

Mutation analysis of $17 \beta$-HSD revealed one single nucleotide polymorphism in each of exons 2, 5, 6, 7 and in the $5^{\prime}$ untranslated region of exon 1 . Three patient samples with high-frequency allele sharing on chromosome 16q had the $\mathrm{a} \rightarrow \mathrm{g}$ polymorphism in exon 2 . All the other samples corresponded to the published sequence being homozygous for $\mathrm{g}$. The $\mathrm{a} \rightarrow \mathrm{g}$ single nucleotide polymorphism in exon 2 did not change the amino acid at this position. One control sample showed a $t \rightarrow c$ polymorphism in exon 5 , but none of the cancer patient samples had this polymorphism. Three samples had an $\mathrm{a} \rightarrow \mathrm{g}$ transition in exon 6: the LNCap cell line and two patients with low-frequency of allele sharing. This polymorphism produced a change in the resulting amino acid from methionine to valine. However, when an additional 12 high-frequency and 12 low-frequency of allele sharing samples were sequenced in this region, no additional samples carried this polymorphism. Therefore, only one cell line and 2 of 44 (4.5\%) prostate cancer patient samples carry this polymorphism. One high-frequency of allele sharing patient sample had a null mutation in exon 7 . This $\mathrm{g} \rightarrow \mathrm{a}$ polymorphism did not produce a change in the amino acid.

A $\mathrm{c} \rightarrow \mathrm{t}$ polymorphism in the $5^{\prime}$ UTR of exon 1 was identified in $40 \%$ of samples tested (10 of 20 high-frequency and 6 of 20 low-frequency samples). Mutations in the 5' UTR have the potential to alter protein translation rates. Of the samples,

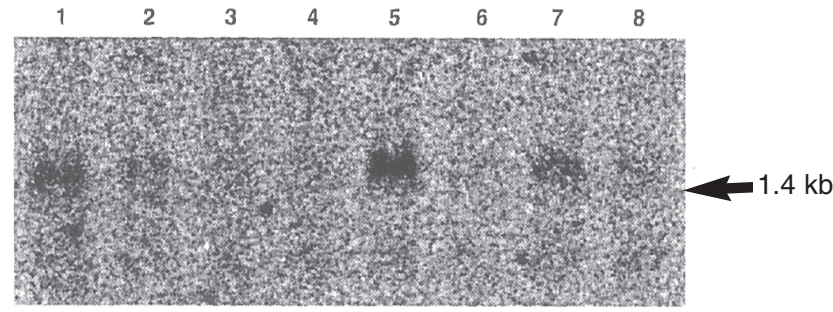

Figure 1. Northern analysis of $17 \beta-H S D$. Samples are:

1) Total Human prostate

2) $\mathrm{LNCaP}$

3) Du145

4) $\mathrm{PC}-3$

5) PZ-HPV-7

6) $\mathrm{Ca}-\mathrm{HPV}-10$

7) PNT2

8) Clonetics normal epithelial cells

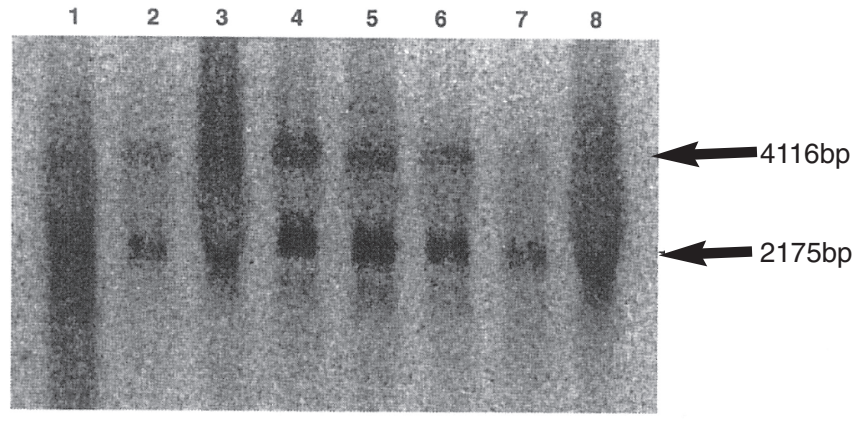

Figure 2. Northern analysis of KIAA 0872 expression in prostate. Samples are the same as figure 1. 
$17.5 \%$ ( 2 of 20 high-frequency and 5 of 20 low-frequency samples) were homozygous $t$ at this position and $42.5 \%$ of samples ( 8 of 20 high-frequency and 9 of 20 low-frequency samples) showed no polymorphism or mutation, remaining homozygous $\mathrm{c}$ at this position.

KIAA 0872 is a novel gene located within the region of linkage on chromosome 16q. Blast analysis of the protein sequence of KIAA 0872 against the sequences in the Swiss Pro protein database failed to show homology between KIAA 0872 and any known proteins (data not shown). Northern results demonstrated expression of KIAA 0872 in normal prostate and each of the cell lines (figure 2), suggesting that sequence analysis of KIAA 0872 for mutations in prostate cancer are warranted. The two bands identified in the Northern blot (figure 2) are consistent with the two cDNAs catalogued in GenBank and likely represent alternate splicing of the same gene.

Mutation analysis of KIAA 0872 revealed two polymorphisms in exon 3. Exons of the KIAA 0872 gene were sequenced in prostate cancer genomic DNA from 18 patients with a high-frequency of allele sharing on chromosome 16 , and 18 patients with a low-frequency of allele sharing in an effort to locate mutations in the protein coding region. In addition, 9 control DNA samples from patients whose cancer status was unknown to the investigators and 3 prostate cancer cell lines were sequenced. The two sites of polymorphism, one at base 1144 and the other at base 1249, were noted with a single base substitution on one or both strands of genomic DNA. None of the base substitutions resulted in a change in the amino acid coding sequence (summary of polymorphisms is in table 4). Interestingly, the polymorphism at base 1249 of the mRNA sequence seems to segregate with families.

Families 4013 and 1349 of the high-frequency samples show this polymorphism, as does the low-frequency sample of family 1349. Family 1349 is a trio of affected sibs, two of whom are identical over the region of interest while the third appears to share neither of his haplotypes with his other two sibs. Two control samples carried the TC polymorphism at base 1249 as did both samples of family 1751 in the low-frequency samples. In total, two prostate cancer families in both high- and low-frequency categories of allele sharing in 16q showed segregation of the TC polymorphism at base 1249 of KIAA 0872 (3' end of exon 3).

\section{DISCUSSION}

Because prostate cancer is a very common cause of disability and death in men, studies of the genetics of this disease are very important. A recent analysis of family and twin studies for cancer concluded that genes contribute high risks for most cancers and that early age at diagnosis is associated with increased familial disease. ${ }^{40}$ Consistent with this, our previous linkage mapping study of affected sib pairs identified at least 8 chromosomal regions that may be important in prostate cancer development.
Of the methods available to identify genes that cause disease, we chose the candidate gene approach. This approach utilizes available information on the function of genes to choose those that may be most likely to carry familial mutations. Because of the pivotal role of androgens in the formation and maintenance of the prostate gland, we first analyzed 17 $\beta$ HSD. We also chose to study KIAA 0872 since the amino acid sequence predicts a novel protein that is unique from other known protein families.

Our results did not identify mutations in the coding region of either of these genes, and the polymorphisms that were identified did not occur in affected individuals at a higher frequency than the controls. We also did not identify mutations in the intron/exon splice sites. However, we cannot rule out the possibility of mutations in the introns or the promoter region of these genes. Most cancer genes identified to date have mutations within the protein-coding region in some of the affected individuals.

Several laboratories have reported LOH on $16 q^{19,41,42}$ near the region identified by linkage mapping of affected families. $\mathrm{LOH}$ is the loss of a region on one copy of the chromosome and frequently occurs at the site of a tumor suppressor gene. As a result of $\mathrm{LOH}$, a patient with one inherited allele becomes null for the tumor suppressor gene due to deletion of the second allele. In a recent study, the putative location of the tumor suppressor gene on chromosome $16 \mathrm{q}$ has been narrowed using $\mathrm{LOH}$ analysis of tumors, ${ }^{43}$ suggesting that it may be possible to refine the search for the prostate cancer gene using this information. Consistent with the $\mathrm{LOH}$ results, the fragile site on chromosome 16 has the same location. ${ }^{44}$ Whether the increase in $\mathrm{LOH}$ at this location on chromosome 16 is the result of chromosomal breaks at the fragile site, or the actual presence of a tumor suppressor gene that is lost during tumor growth, needs to be determined. Neither 17- $\beta$ HSD nor KIAA 0872 are within the narrow region identified by $\mathrm{LOH}$, although they are near the peak identified by linkage mapping.

Our replication study of chromosome 16q using an additional group of prostate cancer patients collected at Marshfield Clinic, University Hospitals of Cleveland, Cleveland Clinic and Washington University Medical School did not add evidence of linkage in this region to a prostate cancer gene. ${ }^{45}$ However, independent analysis of families collected at Marshfield Clinic did support 16q as the location of a gene in familial prostate cancer (unpublished data). In contrast, other whole genome scans of affected patients did not provide evidence of a gene on 16q. ${ }^{25,29}$ The differences in these results are likely to be due to heterogeneity in the genetic background of the patient population, assessment criteria for enrollment of families, and methods used for statistical analysis. 
Table 4. Summary of polymorphisms found in exon 3 of KIAA 0872 mRNA sequence. Bases shown in bold are those segregating with families.

\begin{tabular}{|c|c|c|c|c|c|}
\hline $\begin{array}{l}\text { Sample } \\
\text { Frequency }\end{array}$ & Sample & Base 1144 & Amino Acid & Base 1249 & Amino Acid \\
\hline Standard & GenBank sequence & CC & Valine & TT & Valine \\
\hline Control & 1 & & & CC & Valine \\
\hline Control & 2 & & & CC & Valine \\
\hline Control & 3 & CC & Valine & CC & Valine \\
\hline Control & 4 & & & CC & Valine \\
\hline Control & 5 & & & TC & Valine \\
\hline Control & 6 & & & CC & Valine \\
\hline Control & 7 & & & TC & Valine \\
\hline Control & 8 & & & CC & Valine \\
\hline Control & 9 & & & $\mathrm{CC}$ & Valine \\
\hline Cell line & DU145 & $\mathrm{CC}$ & Valine & $\mathrm{N} / \mathrm{A}$ & \\
\hline Cell line & $\mathrm{LNCaP}$ & $N / A$ & & $\mathrm{CC}$ & Valine \\
\hline Cell line & PC-3 & CC & Valine & CC & Valine \\
\hline High & $4258-03$ & TC & Valine & CC & Valine \\
\hline High & $4258-05$ & $\mathrm{TT}$ & Valine & N/A & \\
\hline High & $4013-03$ & CC & Valine & TC & Valine \\
\hline High & $4013-04$ & $\mathrm{CC}$ & Valine & TC & Valine \\
\hline High & $1886-18$ & $\mathrm{CC}$ & Valine & CC & Valine \\
\hline High & $1886-19$ & CC & Valine & CC & Valine \\
\hline High & $1349-03$ & CC & Valine & TT & Valine \\
\hline High & $1349-04$ & $\mathrm{CC}$ & Valine & TT & Valine \\
\hline High & $4250-03$ & $\mathrm{TT}$ & Valine & CC & Valine \\
\hline High & $450-04$ & TT & Valine & CC & Valine \\
\hline High & $4171-03$ & & & CC & Valine \\
\hline High & $4171-04$ & & & CC & Valine \\
\hline High & $3167-03$ & & & CC & Valine \\
\hline High & $3167-04$ & & & CC & Valine \\
\hline High & $3212-04$ & & & CC & Valine \\
\hline High & $3212-05$ & & & CC & Valine \\
\hline High & $4041-03$ & & & CC & Valine \\
\hline High & $4041-04$ & & & $\mathrm{CC}$ & Valine \\
\hline Low & $4413-05$ & TC & Valine & CC & Valine \\
\hline Low & $4413-03$ & TT & Valine & CC & Valine \\
\hline Low & 4143-05 & TT & Valine & CC & Valine \\
\hline Low & 4143-03 & $\mathrm{CC}$ & Valine & CC & Valine \\
\hline Low & $3790-05$ & $\mathrm{TT}$ & Valine & CC & Valine \\
\hline Low & $3790-03$ & $\mathrm{CC}$ & Valine & CC & Valine \\
\hline Low & $4010-04$ & $\mathrm{TC}$ & Valine & CC & Valine \\
\hline Low & $1349-03$ & $\mathrm{CC}$ & Valine & $\mathrm{TT}$ & Valine \\
\hline Low & $1349-05$ & $\mathrm{TC}$ & Valine & TC & Valine \\
\hline Low & $1349-04$ & $\mathrm{CC}$ & Valine & TT & Valine \\
\hline Low & 3766-04 & & & $\mathrm{CC}$ & Valine \\
\hline Low & $3766-03$ & & & CC & Valine \\
\hline Low & $1911-04$ & & & $\mathrm{CC}$ & Valine \\
\hline Low & $1911-03$ & & & CC & Valine \\
\hline Low & $1751-03$ & & & TC & Valine \\
\hline Low & $1751-04$ & & & $\mathrm{TC}$ & Valine \\
\hline Low & $4209-04$ & & & CC & Valine \\
\hline Low & $4209-03$ & & & CC & Valine \\
\hline
\end{tabular}


Compelling studies suggest that multiple genes are involved in the development of prostate cancer. Although it has proven difficult to date to identify the exact mutations, further studies are indicated to explore the possibility for early diagnosis and treatment of prostate cancer based upon the genetic constitution of the patient.

\section{ACKNOWLEDGMENTS}

We are grateful to Doreen Luepke for expert assistance with the preparation of this manuscript.

\section{REFERENCES}

1. Greenlee RT, Hill-Harmon MB, Murray T, Thun M. Cancer statistics 2001. CA Cancer J Clin 2001;51:15-36.

2. Catalona WJ, Ramos CG, Carvalhal GF. Contemporary results of anatomic radical prostatectomy. CA Cancer J Clin 1999;49:282-296.

3. Meikle AW, Smith JA Jr. Epidemiology of prostate cancer. Urol Clin North Am 1990;17:709-718.

4. Catalona WJ, Smith DS. Detection of early prostate cancer: serendipitous or systematic? JAMA 1998;279:1439-1440.

5. Catalona WJ. Screening for prostate cancer. Early screening is important despite lack of data from trials. Br Med J 1997;315:187.

6. Farkas A, Marcella S, Rhoads GG. Ethnic and racial differences in prostate cancer incidence and mortality. Ethn Dis 2000;10:69-75.

7. Isaacs WB, Bova GS. Prostate cancer. In: Vogelstein B, Kinzler K, editors. The Genetic Basis of Human Cancer, McGraw-Hill, NY, 1998.

8. Mustonen MV, Isomaa VV, Vaskivuo T, Tapanainen J, Poutanen MH, Stenback F, Vihko RK, Vihko PT. Human 17ß-hydroxysteroid dehydrogenase type 2 messenger ribonucleic acid expression and localization in term placenta and in endometrium during the menstrual cycle. J Clin Endocrinol Metab 1998;83:1319-1324.

9. Pienta KJ, Goodson JA, Esper PS. Epidemiology of prostate cancer: molecular and environmental clues. Urology 1996;48:676-683.

10. Li J, Yen C, Liaw D, Podsypanina K, Bose S, Wang SI, Pue J, Miliaresis C, Rodgers L, McCombie R, Bigner SH, Giovanella BC, Ittmann M, Tycko B, Hibshoosh H, Wigler MH, Parsons R. PTEN, a putative protein tyrosine phosphatase gene mutated in human brain, breast, and prostate cancer. Science 1997;275:1943-1947.

11. Sun Z, Pan J, Bubley G, Balk SP. Frequent abnormalities of TSG101 transcripts in human prostate cancer. Oncogene 1997;15:3121-3125.

12. Takahashi S, Shan AL, Ritland SR, Delacey KA, Bostwick DG, Lieber MM, Thibodeau SN, Jenkins RB. Frequent loss of heterozygosity at $7 \mathrm{q} 31.1$ primary prostate cancer is associated with tumor aggressiveness and progression. Cancer Res 1995;55:4114-4119.

13. Trapman J, Sleddens HF, van der Weiden MM, Dinjens WN, Konig JJ, Schroder FH, Faber PW, Bosman FT. Loss of heterozygosity of chromosome 8 microsatellite loci implicates a candidate tumor suppressor gene between the loci D8S87 and D8S133 in human prostate cancer. Cancer Res 1994;54:6061-6064.

14. Gray IC, Phillips SM, Lee SJ, Neoptolemos JP, Weissenbach J, Spurr NK Loss of the chromosomal region 10q23-25 in prostate cancer. Cancer Res 1995;55:4800-4803.

15. Trybus TM, Burgess AC, Wojno KJ, Glover TW, Macoska JA. Distinct areas of allelic loss on chromosomal regions $10 p$ and $10 q$ in human prostate cancer. Cancer Res 1996;56:2263-2267.

16. Ittmann MM. Loss of heterozygosity on chromosome 10 and 17 in clinically localized prostate carcinoma. Prostate 1996;28:275-281.

17. Dahiya R, McCarville J, Lee C, Hu W, Kaur G, Carroll P, Deng G. Deletion of chromosome 11p15, p12, q22, q23-24 loci in human prostate cancer. Inl J Cancer 1997;72:283-288.

18. Cooney KA, Wetzel JC, Merajver SD, Macoska JA, Singleton TP, Wojno KJ. Distinct regions of allelic loss on 13q in prostate cancer. Cancer Res 1996;56:1142-1145

19. Suzuki H, Komiya A, Emi M, Kuramochi H, Shiraishi T, Yatani R, Shimazaki J. Three distinct commonly deleted regions of chromosome arm 16q in human primary and metastatic prostate cancers. Genes Chromosomes Cancer 1996;17:225-233.

20. Gao X, Zacharek A, Salkowski A, Grignon DJ, Sakr W, Porter AT, Honn $\mathrm{KV}$. Loss of heterozygosity of the BRCA1 and other loci in chromosome 17q in human prostate cancer. Cancer Res 1995;55:1002-1005.
21. Macoska JA, Powell IJ, Sakr W, Lane MA. Loss of the 17 p chromosomal region in a metastatic carcinoma of the prostate. J Urol 1992;147:1142-1146.

22. Brothman AR, Steele MR, Williams BJ, Jones E, Odelberg S, Albertsen HM, Jorde LB, Rohr LR, Stephenson RA. Loss of chromosome 17 loci in prostate cancer detected by polymerase chain reaction quantitation of allelic markers. Genes Chromosomes Cancer 1995;13:278-284.

23. Keetch DW, Humphrey PA, Smith DS, Stahl D, Catalona WJ. Clinical and pathological features of hereditary prostate cancer. J Urol 1996;155:1841-1843.

24. Carter BS, Beaty TH, Steinberg GD, Childs B, Walsh PC. Mendelian inheritance of familial prostate cancer. Proc Natl Acad Sci USA 1992;89:3367-3371.

25. Smith JR, Freije D, Carpten JD, Gronberg H, Xu J, Isaacs SD, Brownstein MJ, Bova GS, Guo H, Bujnovszky P, Nusskern DR, Damber JE, Bergh A, Emanuelsson M, Kallioniemi OP, WalkerDaniels J, Bailey-Wilson JE, Beaty TH, Meyers DA, Walsh PC, Collins FS, Trent JM, Isaacs WB. Major susceptibility locus for prostate cancer on chromosome 1 suggested by genome-wide search. Science 1999;274:1371-1374.

26. Berthon P, Valeri A, Cohen-Akenine A, Drelon E, Paiss T, Wohr G, Latil A, Millasseau P, Mellah I, Cohen N, Blanche H, Bellane-Chantelot C, Demenais F, Teillac P, Le Duc A, de Petriconi R, Hautmann R, Chumakow I, Bachner L, Maitland NJ, Lidereau R, Vogel W, Fournier G, Mangin P, Cussenot O, et al. Predisposing gene for early onset prostate cancer, localized on chromosome 1q42.2-2-4.3. Am J Hum Genet 1998;62:1416-1424

27. Xu J, Meyers D, Freije D, Isaacs S, Wiley K, Nusskern D, Ewing C, Wilkens E, Bujnovszky P, Bova GS, Walsh P, Isaacs W, Schleutker J, Matikainen M, Tammela T, Visakorpi T, Kallioniemi OP, Berry R, Schaid D, French A, McDonnell S, Schroeder J, Blute M, Thibodeau $\mathrm{S}$, Trent J, et al. Evidence for a prostate cancer susceptibility locus on the X chromosomes. Nat Genet 1998;20:175-179.

28. Gibbs M, Stanford JL, McIndoe RA, Jarvik GP, Kolb S, Goode EL, Chakrabarti L, Schuster EF, Buckley VA, Miller EL, Brandzel S, Li S, Hood L, Ostrander EA. A rare prostate cancer susceptibility locus mapped to the short arm of chromosome 1 (1p36). Proceed AACR 1999:40:772-773.

29. Gibbs M, Stanford JL, Jarvik GP, Janer M, Badzioch M, Peters MA, Goode EL, Kolb S, Chakrabarti L, Shook M, Basom R, Ostrander EA, Hood L. A genomic scan of families with prostate cancer identifies multiple regions of interest. Am J Hum Genet 2000;67:100-109.

30. Riley DE, Krieger JN. Short tandem repeat polymorphism linkage to the androgen receptor gene in prostate carcinoma. Cancer 2001,92:26032608.

31. Berry R, Schroeder JJ, French AJ, McDonnell SK, Peterson BJ, Cunningham JM, Thibodeau SN, Schaid DJ. Evidence for a prostate cancer - susceptibility locus on chromosome 20. Am J Hum Genet 2000,67:82-91.

32. Carpten J, Nupponen N, Isaacs S, Sood R, Robbins C, Xu J, Faruque M, Moses T, Ewing C, Gillanders E, Hu P, Bujnovszky P, Makalowska I, Baffoe-Bonnie A, Faith D, Smith J, Stephan D, Wiley K, Brownstein M, Gildea D, Kelly B, Jenkins R, Hostetter G, Matikainen M, Schleutker, J, Klinger K, Connors T, Xiang Y, Wang Z, De Marzo A, Papadopoulos N, Kallioniemi OP, Burk R, Meyers D, Gronberg H, Meltzer P, Silverman R, Bailey-Wilson J, Walsh P, Isaacs W, Trent J. Germline mutations in the ribonuclease $\mathrm{L}$ gene in families showing linkage with HPC1. Nat Genet 2002,30:181-184.

33. Tavtigian SV, Simard J, Teng DH, Abtin V, Baumgard M, Beck A, Camp NJ, Carillo AR, Chen Y, Dayananth P, Desrochers M, Dumont M, Farnham JM, Frank D, Frye C, Ghaffari S, Gupte JS, Hu R, Iliev D, Janecki T, Kort EN, Laity KE, Leavitt A, Leblanc G, McArthurMorrison J, Pederson A, Penn B, Peterson K, Reid JE, Richards S, Schroeder M, Smith R, Snyder SC, Swedlund B, Swensen J, Thomas A, Tranchant M, Woodland AM, Labarie F, Skolnick MH, Neuhausen S, Rommens J, Cannon-Albright LA. A candidate prostate cancer susceptibility gene at chromosome 17p. Nat Genet 2001;27:172-180.

34. Rebbeck TR, Walker AH, Zeigler-Johnson C, Weisburg S, Martin AM, Nathanson KL, Wein AJ, Malkowicz SB. Association of HPC2/ELAC2 genotypes and prostate cancer. Am J Hum Genet 2000;67:1014-1019.

35. Suarez BK, Gerhard DS, Lin J, Haberer B, Nguyen L, Kesterson NK, Catalona WJ. Polymorphisms in the prostate cancer susceptibility gene HPC2/ELAC2 in multiplex families and healthy controls. Cancer Res 2001;61:4982-4984. 
36. Suarez BK, Lin J, Burmester JK, Broman KW, Weber JL, Banerjee TK, Goddard KA, Witte JS, Elston RC, Catalona WJ. A genome screen of multiplex sibships with prostate cancer. Am J Hum Genet 2000;66:933-944.

37. Witte JS, Goddard KA, Conti DV, Elston RC, Lin J, Suarez BK, Broman KW, Burmester JK, Weber JL, Catalona WJ. Genomewide scan for prostate cancer - aggressiveness loci. Am J Hum Genet 2000;67:9299.

38. Labrie Y, Durocher F, LaChance Y, Turgeon C, Simard J, Labrie C, Labrie F. The human Type II 17ß-hydroxysteroid dehydrogenase gene encodes two alternatively spliced mRNA species. DNA Cell Biol 1995; 14:849-861.

39. Sambrook J, Russell DW. Molecular Cloning: A Laboratory Manual, $3^{\text {rd }}$ ed. New York : Cold Spring Harbor Laboratory Press, 2001.

40. Risch N. The genetic epidemiology of cancer: Interpreting family and twin studies and their implications for molecular genetic approaches. Cancer Epidemiol Biomarkers Prev 2001;10:733-741.

41. Mashimo T, Watabe M, Cuthbert AP, Newbold RF, Rinker-Schaeffer CW, Helfer E, Watabe K. Human chromosome 16 suppresses metastasis but not tumorigenesis in rat prostatic tumor cells. Cancer Res 1998;58:4572-4576.

42. Elo JP, Harkonen P, Kyllonen AP, Lukkarinen O,Poutanen M, Vihko P. Loss of heterozygosity at 16q24.1-q24.2 is significantly associated with metastatic and aggressive behavior of prostate cancer. Cancer Res 1997;57:3356-3359.

43. Paris PL, Witte JS, Kupelian PA, Levin H, Klein EA $<$ Catalona WJ, Casey G. Identification and fine mapping of a region showing a highfrequency of allelic imbalance on chromosome 16q23.2 that corresponds to a prostate cancer susceptibility locus. Cancer Res 2000;60:3645-3649.

44. Bednarek AK, Laflin KJ, Daniel RL, Liao Q, Hawkins KA, Aldaz CM. WWOX, a novel WW domain-containing protein mapping to human chromosome 16q23.3-24.1, a region frequently affected in breast cancer. Cancer Res 2000;60:2140-2145.

45. Suarez BK, Lin J, Witte JS, Conti DV, Resnick MI, Klein EA, Burmester JK, Vaske DA, Banerjee TK, Catalona WJ. Replication linkage study for prostate cancer susceptibility genes. Prostate 2000;45:106-114. 